\title{
O Controle Disciplinar Exercido pela CGD Sobre a PMCE:
}

uma análise das transgressões cometidas e dos registros de arquivamento/absolvição entre 2011 e 2016

\section{Luiz Paulo Nogueira Lino}

Mestre em Planejamento em Políticas Publicas - UECE

\section{Maria Glaucíria Mota Brasil}

Doutora em Serviço Social pela Pontifícia Universidade Católica de São Paulo

Professora do Programa de Pós-Graduação em Sociologia (PPGS) da UECE

\section{Resumo}

Este trabalho aborda o exercício do controle disciplinar por parte da Controladoria Geral de Disciplina dos Órgãos de Segurança Pública e Sistema Penitenciário (CGD) sobre a atividade policial militar no Ceará, tendo como referência o período compreendido entre os anos 2011 e 2016, haja vista ser aquele ano o primeiro de atuação da CGD e este ano o último que nos fornece dados consolidados acerca das ações desenvolvidas. O foco das observações recai especificamente sobre a quantidade de arquivamentos/absolvições registrados como solução de apurações disciplinares formais (sindicância, procedimento disciplinar-PD, procedimento administrativo-disciplinar-PAD, conselho de disciplina-CD e conselho de justificação-CJ) e sobre as transgressões mais comuns entre os PMs sancionados. Para tanto, foi realizada pesquisa quantitativa junto ao Sistema de Informação ao Cidadão (SIC), canal eletrônico de interação entre poder público e cidadão mantido pela Controladoria e Ouvidoria Geral do Estado (CGE) no Portal da Transparência do Ceará. Com os resultados obtidos pode-se compreender o comportamento dos dados relativos às apurações procedidas contra policiais militares (PMs) na CGD, assim como identificar como evoluíram os registros das espécies de solução acima mencionadas. Portanto, o trabalho expõe uma análise mais aprofundada dessa relação entre PMCE e CGD.

Palavras-chave: Controle Disciplinar. Atividade Policial Militar. Arquivamentos. Absolvições. Transgressões Disciplinares. 


\begin{abstract}
This work deals with the exercise of disciplinary control by the Controller General of Discipline of the Public Security Organs and Penitentiary System (CGD) on military police activity in Ceará, having as reference the period between 2011 and 2016, being that year CGD's first performance and this year the last one that gives us consolidated data about the actions developed. The focus of the remarks is specifically on the number of archiving/acquittals recorded as a solution to formal disciplinary findings (syndication, disciplinary procedure-PD, administrative-disciplinary procedure-PAD, discipline board-CD, and council of justification-CJ) and on the most common transgressions among sanctioned PMs. For that, a quantitative survey was carried out with the Citizen Information Service (SIC), an electronic channel for interaction between public authorities and citizens held by the Controller's Office and State Ombudsman's Office (CGE) at the Transparency Portal of Ceará. With the results obtained it is possible to understand the behavior of the data related to the military police investigations (PMs) in CGD, as well as to identify how the records of the above mentioned species of solution evolved. Therefore, the work exposes a more in-depth analysis of this relationship between PMCE and CGD.
\end{abstract}

Key words: Disciplinary Control. Military Police Activity. Archiving. Acquittals. Disciplinary Transgressions. 


\section{Introdução}

Tratar do controle disciplinar da atividade policial no Ceará nos remete, na verdade, ainda à década de 1990. O primeiro marco importante dessa atividade fiscalizadora foi observado em 1997, quando foi criada pelo governo estadual através da Lei Estadual nº. 12.691, de 16 de maio de 1997, a Corregedoria Geral dos Órgãos de Segurança Pública (CGOSP)', órgão vinculado à Secretaria da Segurança Pública e Defesa Social (SSPDS). A CGOSP fiscalizava a Polícia Militar (PMCE), a Polícia Civil (PCCE) e o Corpo de Bombeiros Militar do Ceará (CBMCE), sendo que, por conta da sua vinculação à Pasta acima citada, ocupava o mesmo patamar que os órgãos fiscalizados e não havia qualquer subordinação entre eles.

Na verdade, a criação da CGOSP significou a adequação do Ceará aos preceitos originários da Constituição Federal de 1988 (CF/88) no sentido de fortalecer a cidadania e aperfeiçoar o serviço público por meio do controle social, este corretamente pontuado por Albuquerque e Machado (2001) como uma forte característica de uma sociedade democrática, como corrobora Bueno (2013), para quem "o controle dos atos públicos significa um pressuposto básico do regime democrático".

É claramente fundamental que agentes que lidam com questões tão sensíveis e possuem atribuições tão importantes tenham a observação constante e vigilante de suas ações.

Como a atividade policial pode incorrer em excessos por fazer uso da força em nome do Estado, exige-se, dessa forma, mecanismos de controle externo para repressão aos eventuais desvios de conduta dos policiais, combate à impunidade e bloqueio das interferências na atividade correicional. (FREIRE, 2009, p. 14).

Exercendo controle interno, a Corregedoria possuía a atribuição tão somente de apurar denúncias de desvio de conduta e, caso restasse comprovado o cometimento de transgressão disciplinar após a apuração formal cabível, sugerir uma sanção ou outra deci-

1 A criação da Ouvidoria Geral do Estado, da Secretaria da Segurança Pública e Defesa da Cidadania e da Corregedoria Geral dos Órgãos de Segurança Pública ocorreu em 1997, no segundo governo de Tasso Jereissati (1995-1998), como parte de uma política implementada na área da segurança pública com o objetivo de enfrentar uma série de crises iniciadas com o chamado "Caso França", que expôs o envolvimento de policiais civis e militares com a corrupção, com o tráfico de drogas e com outros crimes, o que colocou em xeque a cúpula da segurança pública à época. (ver Brasil, 2000). 
são diversa. Logo, o Corregedor-Geral não possuía a atribuição legal de aplicar diretamente qualquer sanção, isso porque as apurações concluídas eram remetidas aos respectivos entes, para que os seus gestores máximos deliberassem acerca da solução final dos feitos.

Apesar de a CGOSP representar um importante avanço para a sociedade cearense, pois a sua existência produziu efeitos positivos iniciais sobre a segurança pública, em especial sobre a PMCE, os anos que se seguiram a 1997 expuseram, paulatinamente, falhas relevantes do, à época, recente trabalho correicional. Tal atividade, aliás, apenas adquiriu importância no contexto nacional com a consolidação da CF/88. Nesse sentido, Brasil e Sousa (2011) relatam que poucas vezes as práticas policiais foram submetidas a avaliações sistemáticas - internas ou externas - ou mesmo foram expostas a críticas diante dos diversos setores sociais.

E sendo a Polícia Militar o maior órgão dentre os fiscalizados, foi consequência natural que também se tornasse o indicador mais fiel desse cenário. $O$ acúmulo de processos disciplinares tornou-se uma constante durante a década passada, o que foi potencializado pela elevação substancial da demanda, principalmente com a implantação do programa Ronda do Quarteirão, responsável pelo incremento de agentes nas fileiras da PMCE. Foram acrescidos cerca de 1.000 policiais militares ao efetivo da Corporação em 2007, assim como em 2009 e 2010. Surge também como um fator importante nessa sucessão de acontecimentos a tentativa de adequação do estado do Ceará ao Plano Nacional de Segurança Pública do Ministério da Justiça, cujas diretrizes contemplavam o aperfeiçoamento do controle disciplinar sobre os órgãos e agentes da segurança pública.

Dessa forma, a defesa de políticas públicas de segurança baseadas no controle disciplinar como forma de reduzir os índices de violência policial passou a ser considerada com mais prioridade (CALDEIRA, 2000; NEME, 1999). Cano (2005) amplia essa visão e fundamenta os seus argumentos a respeito dos aspectos do controle da atividade policial.

Todas as agências públicas precisam de controle social para garantir o cumprimento de suas funções de forma satisfatória. No caso da polícia, depositária do monopólio estatal da violência legítima, esta necessidade é ainda mais peremptória, pois um desvio de conduta pode ter consequências dramáticas. (CANO, 2005, p. 01).

Dado esse contexto instalado no decorrer da década de 2000, de certo descrédito da CGOSP e, principalmente, de agravamento das reclamações em torno do desempenho dos policiais militares cearenses, o governo estadual toma uma decisão importante e cria a Controladoria Geral de Disciplina dos Órgãos de Segurança Pública e Sistema Penitenci- 
ário (CGD) ${ }^{2}$ no ano 2011, um órgão com características singulares, se comparado a todos os outros que exercem a mesma função nos demais estados da Federação. Para tanto, foi necessária a modificação do texto da Constituição do Ceará através da Emenda nº 70/2011³, que acrescentou à referida Carta o art. 180-A, e este, por sua vez, contemplou a Controladoria Geral de Disciplina como um órgão componente da estrutura da administração direta estadual. Naturalmente, foi também necessária a edição de uma norma específica que contivesse os parâmetros legais de organização e de atuação da CGD. Nesse sentido, foi sancionada a Lei Complementar n 98, de 13 de junho de 2011, instrumento que efetivou a criação do órgão de controle e descreveu os seus principais aspectos.

\section{Principais aspectos da criação da CGD}

Devemos ressaltar que a substituição da CGOSP pela CGD não significou apenas uma simples mudança de nomenclatura, pois esta, ao contrário daquela, que era vinculada operacionalmente à SSPDS e não possuía poder decisório sobre os entes fiscalizados, recebeu o status de secretaria de Estado e a atribuição de controle externo disciplinar. A CGD ampliou, ainda, o espectro de atuação do controle disciplinar, na medida em que passaram a compor o rol de fiscalizados os agentes do Sistema Penitenciário. Contudo, destacamos que as atividades de controle são conduzidas por servidores pertencentes

2 o controle interno das polícias no Ceará durante o segundo governo de Cid Ferreira Gomes (2011-2014), mais especificamente em meados de 2011, deixou de ser competência de um órgão de assessoramento da SSPDS Criou-se a CGD para substituir a Corregedoria Geral dos Órgãos de Segurança Pública do Ceará (CGOSPCE), com formato e atuação independentes dos quadros da SSPDS, dotada de autonomia administrativa e financeira e ainda com status de secretaria de Estado. Vinculou-se à Administração Pública Direta e, portanto, ao Poder Executivo, como órgão auxiliar de assessoramento superior (SOUSA, 2014, p. 125). Segundo o mesmo autor, "pode-se conjecturar a ideia de que a reinserção do controle das polícias pode ter sido impulsionada pela letargia nas apurações e pela 'tolerância' ante as denúncias de transgressões policiais, e a constatação pública pela imprensa local da existência de processos disciplinares parados há dez anos”. (ibidem).

3 A Emenda à Constituição Estadual do Ceará nํ. 70/2011 criou o artigo 180-A, que traz a seguinte redação: [o] Poder Executivo instituirá, na forma da lei, a Controladoria Geral de Disciplina dos Órgãos de Segurança Pública e Sistema Penitenciário, de controle externo disciplinar, com autonomia administrativa e financeira, com objetivo exclusivo de apurar a responsabilidade disciplinar e aplicar as sanções cabíveis aos militares da Polícia Militar, militares do Corpo de Bombeiros Militar, membros das carreiras de Polícia Judiciária e membros da carreira de Segurança Penitenciária. 
aos mesmos entes controlados, já que a CGD não possui o seu próprio corpo técnico de agentes efetivos. Por isso, acreditamos muito mais em uma natureza híbrida do órgão, posto que possui, simultaneamente, definição legal de órgão de controle externo com estrutura funcional típica de órgão de controle interno.

Todavia, outras mudanças foram mais claras e notórias. A CGD foi criada como um ente mais autônomo em relação ao Poder Executivo estadual, visto que possui orçamento próprio e subordina-se apenas à figura do governador do Estado, e independente em relação à SSPDS, pois ambas ocupam o mesmo escalão. A distribuição de competências também foi um ponto de inflexão decorrente do surgimento da CGD. O Controlador-Geral de Disciplina4 passou a concentrar atribuições amplas e até mesmo com precedência sobre os gestores máximos dos órgãos controlados, quanto ao aspecto disciplinar. Mas um dos principais objetivos de modificar o controle da atividade policial militar foi a tentativa de aperfeiçoá-la para melhorar a qualidade da segurança pública prestada à sociedade, como expressa o autor mencionado abaixo, que se refere à CGD.

O trabalho de correição desenvolvido é de fundamental importância para o desempenho dos policiais militares, haja vista desencorajar a prática de atos ilícitos por agentes de segurança pública e garantir à sociedade acolhimento e segurança contra desvios de conduta desses profissionais. (SILVA, 2013, p. 06).

De maneira prática, desde 2011 a própria CGD - ao contrário da CGOSP - possui a competência de, além de investigar, aplicar sanções àqueles agentes comprovadamente transgressores. Quanto às sanções mais gravosas previstas na Lei o 13.407/2003 (Código Disciplinar dos Militares Estaduais do Ceará), por exemplo, quais sejam a demissão e a expulsão, apenas o Controlador-Geral de Disciplina possui competência legal sobre as mesmas ${ }^{5}$. Em contrapartida, os Comandantes-Gerais da PMCE e do CBMCE perderam a competência

40 cargo de provimento em comissão de Controlador-Geral de Disciplina, conforme o art. $4^{\circ}$ da Lei Complementar no. 98/2011, é de livre nomeação e exoneração pelo governador do Estado, sendo requisitos para a sua investidura o bacharelado em Direito, conduta ilibada e a ausência de qualquer vínculo funcional com os órgãos da Segurança Pública ou do Sistema Penitenciário. Vale observar, ainda, que predominam entre os nomeados para tal cargo, até então, delegados, da ativa ou aposentados, da Polícia Federal, como Servilho Silva de Paiva e Santiago Amaral Fernandes, que passaram significativos períodos no cargo.

5 Esclarecemos que no caso dos oficiais há um rito peculiar e a competência do Controlador-Geral é mitigada: o oficial submetido a Conselho de Justificação e julgado indigno do oficialato apenas será expulso/demitido após a apreciação da decisão pelo Tribunal de Justiça, sendo que o ato final de afastamento definitivo das fileiras da respectiva corporação é tomado pelo governador do Estado. 
legal de sequer instaurar os processos administrativos que precedem tais decisões (PAD, $\mathrm{CD}$ e $\mathrm{CJ})^{6}$. Além disso, ressaltamos também a capacidade que o Controlador-Geral possui de avocar processos disciplinares originados nos entes fiscalizados, como a PMCE, e rever as suas soluções finais, fazendo prevalecer a sua decisão.

Entretanto, considerando que temos como objeto a observação do trabalho da CGD sobre a PMCE quanto aos procedimentos disciplinares concluídos com arquivamento da denúncia ou absolvição do investigado e também quanto às transgressões mais comprovadamente cometidas, abordaremos pontos próprios desse tema logo após a explanação colocada adiante, que trata das outras formas e fontes de controle do trabalho policial militar como forma de auxiliar a contextualização do objeto de pesquisa no cenário que Ihe é diretamente correlato.

\section{O controle da atividade policial militar no Ceará}

Apesar do foco deste estudo concentrar-se sobre o controle disciplinar exercido em relação à atividade policial militar no Ceará, não podemos deixar de compreender o contexto em que se insere essa relação, ou seja, o gênero correspondente ao controle da atividade policial militar. Nesse sentido, destacamos outros órgãos - além da CGD - que realizam essa atividade fiscalizadora no estado do Ceará, tanto em âmbito interno quanto em âmbito externo. Todavia, é indiscutível que a questão do controle da atividade policial, por seus vários aspectos, é inegavelmente de elevada complexidade (BEATO FILHO, 1999).

Primeiramente, tratamos dos entes de controle externo e citamos o Ministério Público (MP), órgão ao qual cabe a missão constitucional de controlar externamente a atividade policial.

Art. 129. São funções institucionais do Ministério Público: [...] VIII - exercer o controle externo da atividade policial, na forma da lei complementar mencionada no artigo anterior; (CONSTITUIÇÃO FEDERAL DO BRASIL, 1988).

6 o Procedimento Administrativo-Disciplinar, o Conselho de Justificação e o Conselho de Disciplina são três espécies de processo regular previstas no art. 71 da Lei ํㅜ. 13.407/2003 (CDME) com finalidades semelhantes, qual seja apurar as condições do militar permanecer nos quadros de sua corporação. Essas espécies diferenciam-se entre si por seus sujeitos passivos: o PAD é cabível a praças que possuam menos de dez anos de serviço; já o CD abrange as praças que possuam dez anos de serviço ou mais; e o CJ é aplicável exclusivamente aos oficiais, independentemente do tempo de serviço que possuam. 
Porém, parte considerável do controle exercido pelo MP concentra-se sobre as atividades de polícia judiciária (SOUZA, 2001), o que não significa que o MP não exerça controle também sobre os atos realizados no pleno exercício da atividade policial militar, haja vista as investigações já ocorridas em parceria entre o MP local e a Controladoria Geral de Disciplina. Timbó (2015) define como compreende tal função exercida pelo Ministério Público ao enfocar o controle da Polícia Civil do Ceará (PCCE) em seus estudos.

O controle externo da atividade policial realizado pelo Ministério Público deve ser compreendido como esse conjunto de normas que regulam a fiscalização exercida pelo Parquet em relação à Polícia, tendo como objetivos, dentre outros, a defesa dos direitos humanos, a prevenção ou correção de ilegalidades e abuso de poder relativos à atividade de investigação criminal e a probidade administrativa na atividade policial. (TIMBÓ, 2015, p. 39).

Permanecendo no nível externo de controle, há também o tipo de fiscalização exercida pelo Poder Legislativo com o auxílio dos Tribunais de Contas. Fica a cargo de tais entes o controle da administração pública sob os seus aspectos financeiro, patrimonial, contábil e orçamentário, conforme a Seção IX da CF/88. Verificamos, assim, que o exercício dessa competência abrange diretamente as polícias militares e todos os demais entes que compõem a estrutura da administração direta nos estados e no Distrito Federal.

O Tribunal de Contas do Ceará (TCE), em âmbito local, é o responsável por promover as fiscalizações dessa natureza. Mas esse trabalho vai além dos parâmetros supracitados e pode ser replicado para outras searas do poder público. As ações de controle podem afetar fatores mais complexos, como a eficiência da gestão pública, princípio que ganha cada vez mais importância em todo o contexto nacional. Como exemplo e referência para tal observação, apontamos a auditoria operacional realizada pelo TCE sobre a PMCE em meados do ano 2012 sob o escopo de aferir aspectos ligados ao desempenho institucional da Corporação?.

Não podemos deixar de mencionar, ainda, ao Conselho Estadual de Segurança Pública (CONSESP) ${ }^{8}$, criado no âmbito do Poder Executivo estadual em meados do ano 2007 sob a perspectiva de materializar uma política de gestão da segurança pública base-

7 Na ocasião, o Programa Ronda do Quarteirão foi o foco específico dos questionamentos, haja vista o aporte de recursos concentrados pelo poder público em sua implantação desde o ano 2007.

8 o CONSESP possui estrutura de órgão colegiado com 13 membros representativos, os quais possuem as mais diversas origens, como Defensoria Pública, OAB, PMCE, Corpo de Bombeiros, PCCE, Assembleia Legislativa, MP, Câmara Municipal de Fortaleza, entre outros. 
ada na democracia. A ideia do CONSESP era reunir entidades do Estado e da sociedade civil organizada na formatação e na fiscalização das políticas públicas de segurança, o que implicaria a formação de uma espécie de controle externo sobre a atividade policial. Porém, o que observamos atualmente é um órgão pouco atuante e praticamente inócuo no cenário da segurança pública local. Em razão disso, principalmente, podemos considerar o CONSESP como uma medida relegada pelo próprio poder público ao esquecimento em menos de 10 anos.

Já na esfera do controle interno, encontramos um órgão relevante para esta pesquisa, a Controladoria e Ouvidoria Geral do Estado (CGE), Pasta responsável pelo monitoramento do Sistema de Ouvidoria (SOU). No caso do Ceará, o Sistema de Ouvidoria do Poder Executivo caracteriza-se por contemplar o recebimento e o processamento de manifestações e, até mesmo, denúncias recebidas da sociedade sobre a conduta de agentes públicos no exercício de suas funções. Contudo, é válido destacar que o SOU, muito embora receba reclamações desta natureza, não funciona como um campo primário de apuração disciplinar, mas sim como um instrumento de acompanhamento da gestão pública. Mas há autores que divergem desse modelo de ouvidoria e acreditam em órgãos mais autônomos.

\footnotetext{
A Ouvidoria deve ser um órgão autônomo, no sentido de que seu titular seja escolhido por órgão independente do poder fiscalizado. A autonomia precisa ser não apenas funcional, mas também orçamentária. Desse modo, evita-se que a Ouvidoria possa, por exemplo, vir a ser "asfixiada financeiramente", pelo governador de plantão. Ou seja, caso o ouvidor não se comporte de acordo com a vontade do Executivo, ele poderia cortar o fluxo financeiro destinado à instituição. (ZAVERUCHA, 2008, p. 226).
}

A PMCE possui um discreto setor de Ouvidoria vinculado operacionalmente à CGE, cujo responsável - ouvidor - é um agente da própria Corporação. Nesse setor as atividades são exercidas ainda de forma bastante incipiente, dadas as deficiências de autonomia e de estrutura. Quando se trata de reclamação ou denúncia cujo conteúdo abrange atos lesivos à disciplina militar, a Ouvidoria da PMCE exerce o papel de canal de encaminhamento de demanda, pois, nesses casos, cabe-Ihe apenas direcionar o fato aos setores competentes da própria Polícia Militar ou de outros órgãos, como a CGD. Por isso, muitas críticas são feitas ao trabalho desenvolvido pelo SOU e o que se questiona, principalmente, é a sua subutilização ao não atuar disciplinarmente. Fato é que muitos são os entes que fiscalizam a atividade policial e isso é a realidade de vários estados do Brasil, como exemplifica o texto abaixo sobre o Distrito Federal. 


\section{A atividade da CGD sobre a PMCE em números}

Conhecendo as bases da criação da Controladoria Geral de Disciplina e a sua posição no contexto local, prosseguimos com a abordagem específica das principais ações que representam, de fato, o trabalho exercido pelo órgão de controle sobre a PMCE. Partimos do pressuposto que o controle disciplinar realizado pela CGD em relação à atividade policial militar baseia-se em determinados procedimentos operacionais que, se identificados fielmente, são capazes de caracterizar como funciona essa relação entre controlador e controlado.

Buscamos conhecer os principais indicadores dos processos disciplinares procedidos e concluídos no período de referência (2011-2016), tais como o seu quantitativo total, o quantitativo de policiais militares submetidos a esses feitos e o quantitativo de PMs sancionados. Para tanto, realizamos pesquisa quantitativa junto à Controladoria Geral de Disciplina através do Sistema de Informação ao Cidadão (SIC), ferramenta de contato entre Estado e sociedade mantida pelo Sistema de Ouvidoria (SOU) no Portal da Transparência do Ceará.

A coleta de dados ocorreu em dois momentos, sendo que o primeiro tratou de dados relativos às quantidades de procedimentos instaurados e PMs investigados, enquanto o segundo momento tratou dos dados relativos às transgressões mais comuns e aos registros de arquivamento/absolvição entre os policiais militares. 0 primeiro deles correspondeu à solicitação realizada em meados de janeiro do corrente ano. A decorrente resposta foi registrada sob o protocolo virtual no 0362337/2017 e forneceu dados já organizados e devidamente resumidos em tabelas, o que deixou mais claras as informações pretendidas.

No segundo momento, já em meados de agosto, após novo registro de solicitação, a resposta foi registrada sob o protocolo virtual o 6442634/2017. Porém, foram fornecidos, nessa ocasião, dados brutos. Na verdade, foi obtida tão somente uma extensa tabela distribuída em 55 folhas, da qual constavam as principais informações referenciais (número de protocolo, espécie de procedimento, posto/graduação do PM investigado, natureza da solução e número do Diário Oficial com data e número da página de publicação) dos mais de 2.000 procedimentos formalizados na CGD de 2011 a 2016 contra PMs. Diante disso, este 
pesquisador, com o devido auxílio e com base nas referências fornecidas, realizou exaustiva e detalhada pesquisa em todas as edições do Diário Oficial do Estado (DOE) nas quais houvesse publicação de solução punitiva ligada aos mais de 700 casos de sanção, verificando, uma a uma, cada decisão proferida com a aplicação de reprimenda e tabulando os dados identificados.

Em ambos os momentos da pesquisa o procedimento seguido foi semelhante, com o registro inicial de solicitação no endereço eletrônico do Portal da Transparência, cujo encaminhamento foi realizado diretamente à CGD, onde, por sua vez, a Assessoria de Desenvolvimento Institucional foi o setor responsável por colher os dados solicitados e preparar as respectivas respostas, da forma expressa acima. Ressaltamos também que a obtenção dos dados não decorreu de qualquer condição social ou funcional do pesquisador, pois tais tipos de consulta ao poder público são um direito de que dispõe todo cidadão, havendo, para tanto, apenas a restrição aos dados classificados como confidenciais ou sigilosos.

De posse dessas informações, é possível observar as decisões publicadas no DOE quanto às apurações procedidas pela CGD em desfavor de PMs. No ano de criação do Órgão percebemos uma espécie de adequação do novo modelo de controle disciplinar ao contexto estadual, pois os números de procedimentos instaurados e de PMs investigados foi bastante reduzido. Nesse ano foram instaurados 9 processos regulares, o que implicou a investigação de condutas cometidas por apenas 15 policiais militares, sendo 10 por ConseIho de Disciplina, 4 por Sindicância e 1 por Procedimento Administrativo-Disciplinar.

Já no ano seguinte, 2012, verifica-se a elevação notória do número de processos disciplinares instaurados, 187 no total. Figuraram no polo passivo 279 policiais militares. Esse total de PMs investigados foi decorrente da submissão de 169 deles a Sindicância, 59 a Conselho de Disciplina, 45 a Procedimento Administrativo-Disciplinar, 3 a Procedimento Disciplinar e ainda 3 Oficiais a Conselho de Justificação. Sem dúvida, impulsionou esses números a greve dos policiais militares realizada na passagem do ano 2011 para o ano 2012, acontecimento que marcou a segurança pública do Ceará.

Em 2013 os números experimentaram um acréscimo acentuado e chegaram - considerando o tempo de atuação da CGD entre os anos 2011 e 2016 - ao ápice do volume de trabalho correicional registrado até agora. Nesse período foram instaurados 366 procedimentos no total, que culminaram na investigação de 575 policiais militares. Desse universo, 242 PMs responderam a Sindicância, 179 responderam a Conselho de Disciplina, 91 a PAD, 46 a Procedimento Disciplinar e 17 Oficiais foram submetidos a Conselho de Justificação.

No ano 2014, em contraponto, houve decréscimo no número de procedimentos instaurados, sendo 252 ao todo, nos quais figuraram como investigados 424 policiais militares. A divisão por espécie de apuração indica 242 policiais militares submetidos a Sindi-

9 Por conta do movimento paredista deflagrado por parte significativa do efetivo da Polícia Militar do Ceará no ano 2011, a sociedade cearense passou por momentos tensos, sendo que no último dia de greve, 
cância, 129 a CD, 35 a Procedimento Administrativo-Disciplinar, 7 a Procedimento Disciplinar e 10 a CJ. Houve ainda, de acordo com a própria Controladoria Geral de Disciplina, uma demissão ocorrida de forma sumária, decorrente de ordem judicial.

Em 2015 constatamos nova redução na quantidade de processos regulares procedidos pela CGD em comparação com os dois anos anteriores. No total, foram instaurados 209 procedimentos em desfavor de 331 policiais militares, sendo que 154 foram investigados por Sindicância, 114 por Conselho de Disciplina, 31 por PAD, apenas 3 por Procedimento Disciplinar e 29 Oficiais por Conselho de Justificação. Com relação ao aumento expressivo de Oficiais submetidos a Conselho de Justificação, observamos que a maioria deles incorreu na mesma acusação, que foi decorrente da participação em um vídeo de manifesto de apoio à campanha eleitoral de um candidato ao cargo de deputado estadual no pleito local de 2014.

Por fim, em relação a 2016, último ano do período analisado, constatamos nova elevação dos números demonstrativos do desempenho apuratório da CGD, não igual a 2013, mas aproximando-se bastante dos números referentes a 2014. Foram instaurados 239 procedimentos administrativos em desfavor de 410 policiais militares, dos quais 352 foram sob a forma de Sindicância, 44 sob a forma de Conselho de Disciplina, 9 sob a forma de Procedimento Administrativo-Disciplinar, $2 \mathrm{sob}$ a forma de Procedimento Disciplinar e apenas 3 sob a forma de Conselho de Justificação. Verificamos da série exposta que não há constância no trabalho de controle sobre a atividade policial militar em seu viés investigativo, mas sim uma complexidade considerável demonstrada pelos números apresentados.

Para que tenhamos uma compreensão sistematizada das informações expressas acima, elaboramos o gráfico seguinte, do qual consta a evolução dos dados ano a ano.

\section{Gráfico 1 - Procedimentos instaurados no âmbito da CGD (2011-2016)}

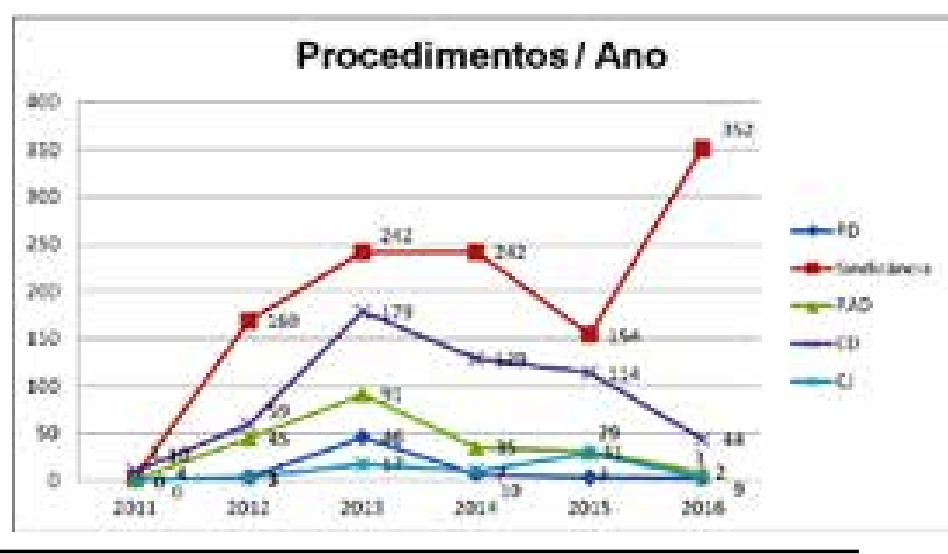

Fonte: elaboração própria com base em dados oriundos da CGD (2017).

03/01/2012, comércio, escolas, bancos e até a Prefeitura de Fortaleza encerraram suas atividades de forma abreviada devido aos caos instalado. (PORTAL DE NOTíCIAS G1, 04/01/2012). Depois desses acontecimentos, como uma decorrência direta, os principais líderes da categoria naquela ocasião chegaram a cargos eletivos no Poder Legislativo, em suas três esferas. 
Sob o mesmo escopo do Gráfico 1, adiante fazemos referência aos números correspondentes ao total de procedimento instaurados no âmbito da Controladoria Geral de Disciplina - considerando as cinco espécies já descritas - e ao quantitativo geral de policiais militares submetidos a esses processos.

\section{Gráfico 2 - Procedimentos instaurados X PMs investigados (2011-2016)}

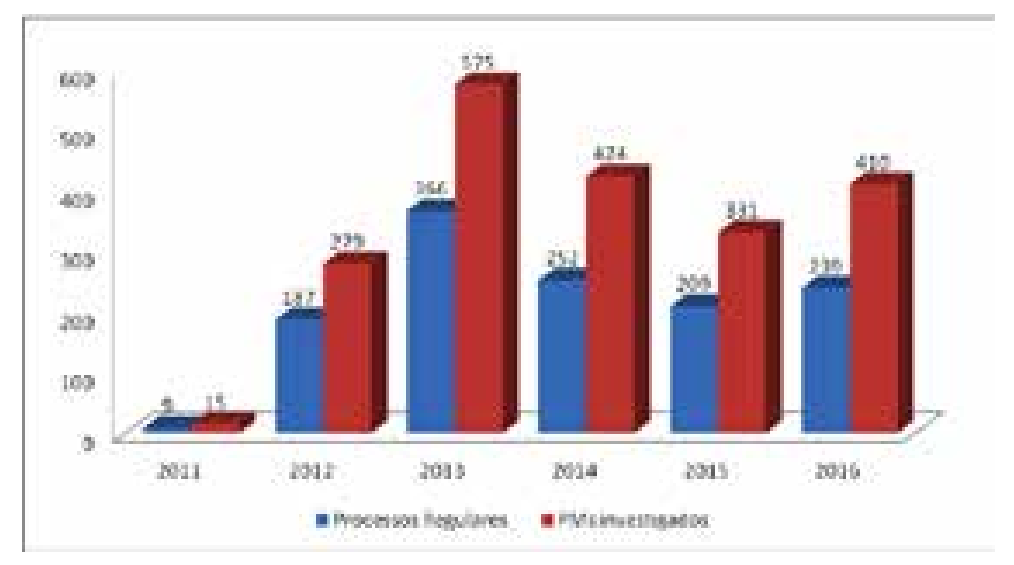

Fonte: elaboração própria com base em dados oriundos da CGD (2017)

Tratados os procedimentos apuratórios inerentes ao controle disciplinar, voltamos o foco para outra variável relevante e passamos a analisar a aplicação de sanções disciplinares aos PMs, tomando como base as decisões proferidas pela Controladoria Geral de Disciplina com publicação no DOE, meio que confere plena eficácia aos atos tomados pelo órgão de controle. Nesse contexto, verificamos os instrumentos mais incisivos de controle disciplinar, quais sejam as punições administrativas aplicadas a um PM comprovadamente transgressor.

No ensejo, especificamos os gêneros de solução - absolvição, arquivamento ou sanção - cabíveis aos procedimentos administrativos. Seguindo uma ordem crescente de rigor, temos como o tipo mais brando de sanção a Repreensão, que se limita apenas a um simples registro escrito nos assentamentos funcionais do sancionado. A próxima espécie punitiva é a chamada Permanência Disciplinar, sanção que implica a restrição da liberdade de ir e vir como uma de suas consequências, contudo, permite que o sancionado execute suas funções profissionais ao deixá-lo restrito apenas ao ambiente do quartel. A Custódia Disciplinar, por sua vez, difere-se da Permanência por ser medida mais gravosa e exigir que o sancionado seja recolhido a um local específico - devendo ser uma cela, se o quartel tiver estrutura física compatível -, devendo permanecer com sua liberdade totalmente restrita, ou seja, sem participar, sequer, das suas atividades profissionais. Outra forma de punição ocorre através da Reforma Disciplinar, que consiste no afastamento total do serviço ativo 
por motivo que impeça o desempenho das missões inerentes à carreira policial militar, mas não embase a aplicação de sanções diversas, consistindo na inativação punitiva do sancionado.

Por fim, temos as duas espécies de reprimenda mais gravosas, cujos efeitos alcançam o extremo da esfera administrativa ao provocar a perda do cargo público para o PM punido, sendo tais sanções a demissão e a expulsão. Apesar de provocarem efeitos semelhantes ao sancionado, ambas as sanções apresentam-se diferentes quanto às situações que ensejam a sua aplicação. Com base nas informações colocadas, iniciamos a explanação pelo ano 2011, quando 15 PMs foram investigados. Desse total, houve 3 absolvições e, por outro lado, 12 profissionais foram sancionados disciplinarmente, dos quais 2 foram repreendidos, 6 foram punidos com permanência disciplinar e 4 foram demitidos/expulsos.

No ano seguinte, em 2012, observamos um incremento substancial no número de policiais militares investigados, que totalizou 279, dos quais 123 PMs tiveram os seus processos arquivados e 15 foram absolvidos, o que implica a não aplicação de reprimenda em ambas as decisões. Do restante, cujas decisões foram de caráter punitivo, houve 4 repreensões, apenas 1 reforma administrativa, 101 permanências disciplinares, 11 custódias, 5 exclusões e 19 demissões/expulsões. Para fins de esclarecimento, vale ressaltar que as exclusões consistem no afastamento total da PMCE a título de pena decorrente de uma decisão judicial.

Já em 2013, de forma semelhante aos parâmetros anteriores, registrou-se quantidade de procedimentos bastante elevada em desfavor de policiais militares, o que, inevitavelmente, afetou a quantidade de sanções aplicadas aos mesmos. Dos 575 PMs investigados apenas 2 foram absolvidos, mas 295 tiveram os seus processos arquivados. Em contrapartida, 17 sofreram repreensão, 4 foram reformados administrativamente, 183 sofreram permanência disciplinar, 19 sofreram custódia disciplinar, além de 1 excluído e 54 demitidos/ expulsos.

No ano 2014, por sua vez, observamos a completa ausência de registros de absolvição e exclusão. Ainda assim, tivemos 424 policiais militares investigados. Desse total, 258 foram inocentados e tiveram suas apurações arquivadas. Outros $29 \mathrm{PMs}$ foram sancionados com repreensão, 3 foram sancionados com reforma administrativa, 89 sancionados com permanência disciplinar, 14 punidos com custódia disciplinar e 31 com demissão/expulsão.

Tendência ainda mais acentuada de redução dos registros de punições foi verificada por ocasião da análise dos números correspondentes ao ano 2015, quando, dos 331 policiais militares investigados formalmente, 251 tiveram a denúncia arquivada e o restante sofreu alguma espécie de reprimenda, com 16 repreensões, 57 permanências disciplinares, 6 custódias e somente 1 demissão/expulsão. Não houve nesse ano registros de absolvição, reforma administrativa ou exclusão. 
Por fim, no ano 2016, foram 410 policiais militares submetidos a procedimentos apuratórios, sendo que, desse total, 341 tiveram a denúncia arquivada, 10 foram punidos com repreensão, 2 foram sancionados com reforma administrativa, 51 com permanência disciplinar, 3 com custódia disciplinar e apenas 3 sofreram demissão/expulsão. Na tabela abaixo resumimos os dados expostos na série ora concluída.

Tabela 1 - Soluções aplicadas aos processos disciplinares

\begin{tabular}{|c|c|c|c|c|c|c|}
\hline SOLUÇÕES DAS INVESTIGAÇÕES / ANO & 2011 & 2012 & 2013 & 2014 & 2015 & 2016 \\
\hline Absolvição & 3 & 15 & 2 & 0 & 0 & 0 \\
\hline Arquivamento & 0 & 123 & 295 & 258 & 251 & 341 \\
\hline Custódia Disciplinar & 0 & 11 & 19 & 14 & 6 & 3 \\
\hline Demissão / Expulsão & 4 & 19 & 54 & 31 & 1 & 3 \\
\hline Exclusão $\left(^{*}\right)$ & 0 & 5 & 1 & 0 & 0 & 0 \\
\hline Permanência Disciploladoria Geral de Disciplina (2017). \\
\hline Reforma Administrativa & 6 & 101 & 183 & 89 & 57 & 51 \\
\hline Repreensão & 0 & 1 & 4 & 3 & 0 & 2 \\
\hline №. TOTAL DE SERVIDORES INVESTIGADOS & 15 & 279 & 575 & 424 & 331 & 410 \\
\hline №. TOTAL DE SERVIDORES PUNIDOS & 12 & 141 & 278 & 166 & 80 & 69 \\
\hline
\end{tabular}

Constatamos, assim, que o arquivamento é a forma de resolução mais comum, seja por ausência de provas, por desistência do denunciante ou por outro motivo que não permita prosperar a denúncia formulada. Em termos absolutos, aliás, observamos que, dos 2.034 procedimentos instaurados na CGD em desfavor de PMs entre 2011 e 2016 com solução publicada no DOE, 1.288 foram concluídos com arquivamento ou absolvição. Por outro lado, houve 746 registros de sanções disciplinares. Esses totais representam, respectivamente, $63,32 \%$ e $36,68 \%$, estando incluídos os procedimentos voltados tanto para praças como para oficiais.

Nesse contexto, destacamos, sobretudo, uma tendência relevante observada na evolução do número e do percentual de casos de arquivamento e absolvição registrados: a representatividade relativa dessas espécies de solução demonstram ascensão significativa no período de referência. 
Gráfico 3 - Arquivamentos/absolvições entre PMs na CGD (2011-2016)

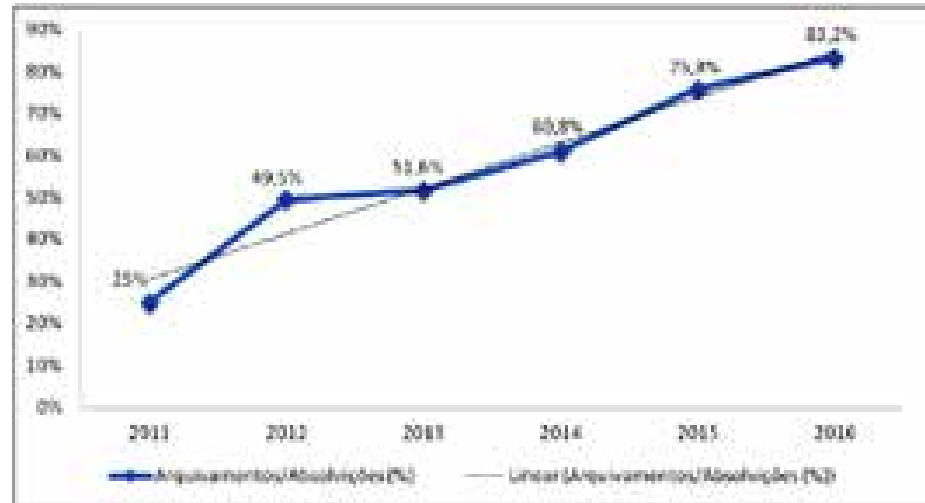

Fonte: elaboração própria com base em dados oriundos da CGD (2017)

Por fim, tratamos das espécies mais comuns de transgressão disciplinar entre os policiais militares sancionados no período de referência. Utilizamos como base de análise os mesmos dados já registrados anteriormente acerca das sanções aplicadas tanto a praças como oficiais. Tendo em vista a melhor compreensão dos dados, delimitamos, em termos absolutos, as 5 (cinco) condutas transgressoras mais cometidas pelos PMs faltosos: agressão física/lesão corporal, ameaça, disparo de arma de fogo, porte ilegal de arma de fogo e abuso de autoridade.

\section{Gráfico 4 - As cinco transgressões disciplinares mais comuns entre PMs (2011-2016)}

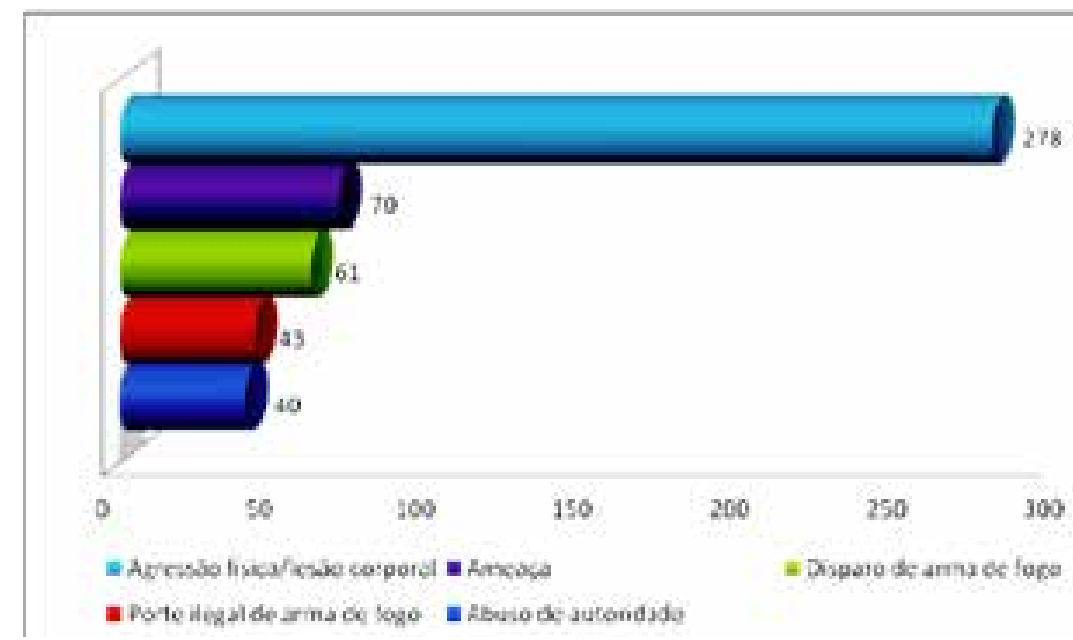

Dessa forma, encerramos a exposição dos dados pesquisados acerca do controle disciplinar exercido pela CGD sobre a Polícia Militar, especificamente no que tange às transgressões mais cometidas e aos registros de arquivamentos e absolvições ocorridos no período de interesse, considerando que esses parâmetros são, de fato, representativos para a compreensão da atuação efetiva do órgão de controle sobre os policiais militares cearenses. 


\section{Considerações Finais}

Após a análise dos dados apresentados acima, obtidos com a realização de pesquisa quantitativa, de pesquisa documental - por meio da observação das normas que regem as atividades da CGD e da PMCE - e de pesquisa bibliográfica - através da leitura e da compreensão dos autores referenciados -, chegamos aos resultados do trabalho desenvolvido. Conforme mencionamos, os dados referentes às transgressões mais frequentes nas sanções aplicadas aos PMs foram fornecidos em seu estado mais bruto, pois não havia acompanhamento detalhado nem tratamento de tais dados. A partir de tal fato, concluímos que a própria Controladoria Geral de Disciplina desconhece as principais infrações cometidas por policiais militares e com as quais lida cotidianamente, algo que deveria ser elementar.

Constatamos também que a CGD concentra seus esforços operacionais no enfrentamento direto aos casos de má conduta através de processos regulares, o que também ocorre quanto à PMCE e acaba por relegar ao segundo plano as ações preventivas e de orientação, que poderiam ser realizadas sistematicamente junto aos agentes fiscalizados. Sendo assim, os procedimentos disciplinares assumem o papel de principal ferramenta de controle efetivo e as sanções assumem o papel de principal instrumento de correição.

Outro importante fato observado foi que a maior parte das apurações formalizadas no âmbito da CGD em desfavor de policiais militares é solucionada com o arquivamento do processo ou a absolvição do investigado. Mais precisamente, das 2.034 investigações concluídas no período de referência, 1.288 tiveram como resultado arquivamento/absolvição, ou seja, 63,3\% do total. O percentual de arquivamentos/absolvições entre PMs, aliás, demonstra clara tendência de crescimento entre 2011 e 2016, chegando aos mais de 80\% do total de soluções no último ano. Por fim, identificamos as cinco transgressões mais cometidas pelos policiais militares no mesmo período, ou seja, aquelas condutas que mais demandaram a intervenção punitiva da CGD diante de uma afronta à disciplina funcional: agressão física/lesão corporal, ameaça, disparo de arma de fogo, porte ilegal de arma de fogo e abuso de autoridade. 


\section{Referências Bibliográficas}

ALBUQUERQUE, Carlos Linhares de; MACHADO, Eduardo Paes. Sob o signo de Marte: modernização, ensino e ritos da instituição policial militar. 2001.

ALMEIDA, Juniele Rabêlo de. Policiais Militares Brasileiros: ciclo de protestos e punições corporativas. XXIV Simpósio Nacional de História, 2007.

BEATO FILHO, Cláudio C. Políticas públicas de segurança e a questão policial. São Paulo em Perspectiva, v. 13, n. 4, p. 13-27, 1999.

BRASIL. Constituição (1988). Constituição da República Federativa do Brasil: promulgada em 05 de outubro de 1988.

BRASIL, Maria Glaucíria Mota et al. A segurança pública no “Governo das Mudanças”: moralização, modernização e participação. Tese de Doutorado. Pontifícia Universidade Católica de São Paulo. 2000.

BRASIL, Maria Glaucíria Mota; SOUSA, Emanuel Bruno Lopes de. Resistências às mudanças na corporação policial: a experiência do programa Ronda do Quarteirão no Ceará. O público e o privado, n. 15, 2011.

BUENO, Samira. Controle social da atividade policial: A experiência da primeira ouvidoria de polícia do país. Brasília: Congresso de Gestão Pública, 2013.

CALDEIRA, Teresa. Cidade de muros: crimes, segregação e cidadania em São Paulo. São Paulo: EDUSP, 2000.

CANO, Ignácio. Controle de polícia no Brasil. Conferência Internacional Controle da Polícia 
e a Qualidade do Monitoramento: tendências globais e contextos nacionais. Haia: Aliança Global, 2005.

CEARÁ. Constituição (1989). Constituição Estadual do Ceará: promulgada em 05 de outubro de 1989, com as alterações dadas até a Emenda Constitucional no 74/2012. Fortaleza, CE: Assembleia Legislativa do Estado do Ceará, 2012. 98 p.

. Controladoria Geral de Disciplina dos Órgãos de Segurança Pública e Sistema Penitenciário. Lei Complementar no 98, de 13 de junho de 2011. Dispõe sobre a criação da Controladoria Geral de Disciplina dos Órgãos de Segurança Pública e Sistema Penitenciário, acrescenta dispositivo à Lei no 13.875, de 7 de fevereiro de 2007 e dá outras providências. Fortaleza, 2011.

Secretaria da Segurança Pública e Defesa Social. Lei no 13.407, de 21 de novembro de 2003. Institui o Código Disciplinar da Polícia Militar do Ceará e do Corpo de Bombeiros Militar do Ceará, dispõe sobre o comportamento ético dos militares estaduais, estabelece os procedimentos para apuração da responsabilidade administrativo-disciplinar dos militares estaduais e dá outras providências. Fortaleza, 2003.

Corregedoria Geral dos Órgãos de Segurança Pública. Lei no 12.691, de 16 de maio de 1997. Cria a Secretaria da Segurança Pública e Defesa da Cidadania e a Corregedoria Geral dos Órgãos de Segurança Pública, extingue a Secretaria da Segurança Pública e a Corregedoria Geral da Polícia Civil, dispõe sobre a Polícia Civil, Polícia Militar, Corpo de Bombeiros e dá outras providências. Fortaleza, 1997.

FREIRE, Alice de Almeida (Coord.). Manual Nacional do Controle Externo da Atividade Policial. Goiânia: MP, 2009.

MINAYO, Maria Cecília de Souza. Pesquisa social: teoria, método e criatividade. 28a Edição. Petrópolis: Editora Vozes, 2009.

NEME, Cristina. A instituição da polícia na ordem democrática: o caso da Polícia Militar do 
Estado de São Paulo. Dissertação de Mestrado. Universidade de São Paulo. 1999.

SILVA, Christyne Carvalho da. Relacionamento entre os controles internos e externos da

Polícia Militar do Distrito Federal: motivações e perspectivas. 2008.

SILVA, Francinilson Mota da. 0 impacto da Controladoria no tempo de julgamento dos processos disciplinares dos policiais militares do Ceará. Dissertação de Mestrado. Universidade Federal do Ceará. 2013.

SOUSA, Emanuel Bruno Lopes de. Controle das polícias: agendas, reformas e (novas) práticas. Rio de Janeiro, 2014. 242p. Tese (Doutorado em Política Social) - Programa de Pós-Graduação em Política Social. Universidade Federal Fluminense. 2014.

SOUZA, João Ricardo Carvalho de. Controle externo da atividade policial. Estudo das Consultorias. Brasília: Câmara dos Deputados, 2001.

TIMBÓ, Wander de Almeida. O Controle Externo da Atividade Policial como Instrumento de Efetivação de Políticas Públicas de Segurança. Fortaleza, 2015. 101p. Dissertação (Mestrado em Políticas Públicas e Sociedade). Universidade Estadual do Ceará. 2015.

TRINDADE, Arthur; PORTO, Maria Stela Grossi. Controlando a atividade policial: uma análise comparada dos códigos de conduta no Brasil e Canadá. Sociologias, v. 13, n. 27, 2011.

ZALUAR, Alba. Democratização inacabada: fracasso da segurança pública. Estudos Avançados, v. 21, n. 61, p. 31-49, 2007.

ZAVERUCHA, Jorge et al. O papel da ouvidoria de polícia. Sociologias, v. 10, n. 20, p. 224-235, 2008. 